\title{
PROFIL MASYARAKAT DAN LINGKUNGANNYA SEBAGAI MODAL MEMBANGUN PERAN SERTA MASYARAKAT DALAM UPAYA PENCEGAHAN PENCEMARAN LINGKUNGAN
}

\section{SOCIETY AND ENVIRONMENTAL PROFILE AS PUBLIC PARTICIPATION DEVELOPMENT IN POPULATION PREVENTION}

\author{
Sri Unon Purwati dan Melania Hanny Aryantie ${ }^{1}$
}

(Diterima tanggal 22-06-2016; Disetujui tanggal 10-11-2016)

\begin{abstract}
ABSTRAK
Peran serta masyarakat menjadi suatu yang mutlak dalam kerangka menciptakan lingkungan hidup yang sehat. Peran serta masyarakat tidak saja digunakan sebagai sarana untuk mencapai tujuan, tetapi juga digunakan sebagai tujuan. Keterlibatan masyarakat sebagai penghasil terbesar limbah rumah tangga yang mencemari badan air (sungai) untuk mengelola limbahnya menjadi sangat penting agar tercipta lingkungan hidup yang sehat. Memanfaatkan profil masyarakat sebagai modal peningkatan peran serta masyarakat dalam upaya pencegahan pencemaran air merupakan permasalahan yang penting pada penelitian ini. Kuesioner digunakan sebagai alat untuk memperoleh data primer yang dibutuhkan dengan tujuan mengetahui profil masyarakat dan lingkungan di lokasi penelitian serta menentukan strategi pemanfaatan profil tersebut sebagai modal meningkatkan peran serta masyarakat dalam upaya pencegahan pencemaran lingkungan air. Penelitian dilakukan tahun 2015 di Perumahan Permata Depok, Kota Depok Kecamatan Cipayung Kelurahan Pondok Jaya khususnya Mirah 1 dan 2 meliputi RT 6 dan11 RW 07, berada di tepi Sungai Ciliwung dengan bentuk saluran sanitasi yang terpusat (komunal) bermuara di Sungai Ciliwung. Aparat pemerintah daerah bersifat terbuka, mendukung program pengelolaan lingkungan tetapi masih kurang bantuan sarana pendukung dan pembinaan dari pemerintah. Masyarakat daerah penelitian berstatus ekonomi menengah ke atas, bergaya hidup modern, usia produktif, mendukung program pengelolaan lingkungan, paham peraturan terkait lingkungan tetapi memiliki kemauan berpartisipasi membayar (willingness to pay) yang masih rendah. Berdasarkan profil yang diperoleh tersebut maka ditentukan bahwa strategi yang tepat yang akan digunakan dalam rangka peningkatan peran serta masyarakat dalam upaya pencegahan pencemaran air adalah secara edukatif. Strategi edukatif berupa penyuluhan terkait pengelolaan limbah domestik sesuai karakteristik limbah yang dihasilkan oleh masyarakat. Pendekatan strategi teknologi tidak menutup kemungkinan untuk dilakukan berupa teknologi sederhana dan ramah lingkungan sesuai dengan profil masyarakat di lokasi penelitian.
\end{abstract}

Kata kunci : profil lingkungan, profil aparatur pemerintah, profil masyarakat, peningkatan peran serta masyarakat, pencegahan pencemaran, strategi edukatif, Sungai Ciliwung.

\begin{abstract}
Community participation becomes an absolute in terms of creating a healthy environment. Community participation is not only used as a means to an end, but also used as a destination. Community involvement as the largest producer of household waste that pollutes water bodies (rivers) to manage the wastes to be very important in order to create a healthy living environment. Utilizing public profile as a capital increase community participation in the prevention of water pollution is an important issue in this study. A questionnaire was used as a tool to obtain primary data that is required in order to know the profile of society and the environment in the study site and determine the strategy for the utilization of the profile as a capital increase community participation in efforts to prevent pollution of the water environment. The study was conducted in 2015 in the Housing Permata Depok, Depok City District of Pondok Jaya Village Cipayung especially Mirah 1 and 2 include dan11 RT 6 RW 07, is in the Ciliwung riverbank to form a centralized sanitary sewer (communal) rests on the Ciliwung River. Local government officials are open, supportive environment management program but still lacking means of support and coaching assistance
\end{abstract}

\footnotetext{
${ }^{1}$ Pusat Penelitian dan Pengembangan Kualitas dan Laboratorium Lingkungan. Kaw. Puspiptek Gedung 210, Jl. Raya Puspiptek, Serpong,

Tangsel, Prov. Banten. Fax/Telp. (021) 7560981, unon.purwati@gmail.com,melania.hanny@gmail.com
} 
from the government. Community research areas upper middle economic status, life style modern, productive age, supporting the environmental management program, understand the rules relating to the environment but has participated willingness to pay (willingness to pay) is still low. Based on the profile obtained is then determined that the appropriate strategy to be used in order to increase community participation in the prevention of water pollution is as educative. Educational strategies in the form of counseling related to domestic waste management according to the characteristics of waste generated by the community. Approach to technology strategy it is possible to do such a simple technology and environmentally friendly in accordance with the public profile of the study sites.

Keywords: environmental profile, profile government officials, community profiles, community articipation, pollution prevention, educational strategies, the Ciliwung River.

\section{PENDAHULUAN}

Pertumbuhan penduduk yang semakin meningkat akan berpengaruh pada ketersediaan sumberdaya alam dan berpengaruh juga pada dampak lingkungan. Semakin banyak penduduk maka semakin banyak kebutuhan hidup yang harus dipenuhi dari sumberdaya alam yang ada, dengan demikian maka pemenuhan kebutuhan dasar tidak hanya mengandalkan hasil pertanian, perikanan dan peternakan, akan tetapi pemenuhan kebutuhan akan mengarah pada eksploitasi sumberdaya laut, hutan, tambang dan lain-lain. Jika eksploitasi terhadap sumberdaya alam tidak mengacu pada analisis dampak lingkungan akan menimbulkan persoalan lingkungan untuk masa datang dan menimbulkan bahaya berupa bencana alam.

Peran serta masyarakat dalam pengelolaan lingkungan hidup menjadi kebutuhan dasar semua orang yang secara fisik berada dalam lingkungan hidup yang berubah, dalam arti terus menurunnya kualitas lingkungan. Peran serta masyarakat menjadi suatu yang mutlak dalam kerangka menciptakan lingkungan hidup yang sehat. Peran serta masyarakat tidak saja digunakan sebagai sarana untuk mencapai tujuan, tetapi juga digunakan sebagai tujuan (participation is an end itself) (1). Syarat agar masyarakat bisa berperan serta dalam pengelolaan lingkungan adalah:
1. Pemimpin eksekutif yang terbuka

2. Peraturan yang akomodatif

3. Masyarakat yang sadar lingkungan

4. Lembaga swadaya masyarakat yang tanggap

5. Informasi yang cepat

6. Keterpaduan antar instansi terkait (Koesnadi Harjosumantri, 1986) dalam(2)

Undang-undang No. 32 Tahun 2009 tentang Perlindungan dan Pengelolaan Lingkungan Hidup telah mendefinisikan beberapa pasal yang terkait dengan pencegahan pencemaran lingkungan, yakni:Pasal 13 . Pasal 13 Ayat (3) Pengendalian pencemaran dan/atau kerusakan lingkungan hidup sebagaimana dimaksud pada ayat (1) dilaksanakan oleh Pemerintah, pemerintah daerah, dan penanggung jawab usaha dan/atau kegiatan sesuai dengan kewenangan, peran, dan tanggung jawab masing-masing.

1. Pasal 14 Instrumen pencegahan pencemaran dan/atau kerusakan lingkungan hidup terdiri atas: c. baku mutu lingkungan hidup;

2. Pasal 20 Ayat (3) Setiap orang diperbolehkan untuk membuang limbah ke media lingkungan hidup dengan persyaratan: a. memenuhi baku mutu lingkungan hidup (3).

Berdasarkan pada dasar hukum di atas maka 
penyelesaian masalah pencemaran terdiri dari langkah pencegahan dan pengendalian. Langkah pencegahan pada prinsipnya mengurangi pencemar dari sumbernya untuk mencegah dampak lingkungan yang lebih berat. Langkah pengendalian sangat penting untuk menjaga lingkungan tetap bersih dan sehat. Pengendalian dapat berupa pembuatan standar baku mutu lingkungan, pemantauan (monitoring) lingkungan dan penggunaan teknologi untuk mengatasi masalah lingkungan.

Pada dasarnya ada tiga cara pendekatan yang dapat dilakukan dalam rangka pencegahan pencemaran lingkungan, yaitu:

\section{Secara Administratif}

Upaya pencegahan pencemaran lingkungan secara administratif adalah pencegahan pencemaran lingkungan yang dilakukan oleh pemerintah dengan cara mengeluarkan kebijakan atau peraturan yang berhubungan dengan lingkungan hidup.

\section{Secara Teknologis}

Cara ini ditempuh dengan mewajibkan pabrik untuk memiliki unit pengolahan limbah sendiri. Sebelum limbah pabrik dibuang ke lingkungan, pabrik wajib mengolah limbah tersebut terlebih dahulu sehingga menjadi zat yang tidak berbahaya bagi lingkungan.

\section{Secara Edukatif}

Cara ini ditempuh dengan melakukan penyuluhan terhadap masyarakat akan pentingnya lingkungan dan betapa bahayanya pencemaran lingkungan (4).

Strategi pengendalian pencemaran khususnya air sungai difokuskan pada: a. Peningkatan peran masyarakat baik masyarakat umum, petani maupun industri dalam upaya pengendalian pencemaran air.

b. Peningkatan koordinasi antar instansi yang berkaitan dengan pengendalian pencemaran air, serta

c. Mengintegrasikan kebijakan pengendalian pencemaran air dalam penataan ruang (5).

Pengendalian pencemaran sungai dipilih karena merupakan kegiatan eselon I Kementerian Lingkungan Hidup dan Kehutanan, yaitu menurunkan kandungan BOD, COD, dan E. coli di Sungai Ciliwung, Citarum dan Cisadane.

Strategi dalam pengendalian pencemaran yang difokuskan pada peningkatan peran masyarakat dalam upaya tersebut terdapat saling keterkaitan antara sarana, teknologi dan perilaku masyarakat (6). Ada beberapa jenis peran serta masyarakat terhadap lingkungan antara lain peran serta dalam pemeliharaan dan perbaikan mutu lingkungan dengan kesadaran masyarakat akan kebutuhan dan nilai suatu lingkungan yang sehat (6). Peran serta masyarakat jelas dibutuhkan seperti hasil penelitian Susmarkanto (t.t.) dalam (7) bahwa $80 \%$ sumber pencemaran sungai yang mengalir di Jakarta berasal dari limbah rumah tangga dan hanya $20 \%$ yang berasal dari buangan limbah industri. Dari sini terlihat bahwa selain pemerintah dan sektor swasta (industri) perlu adanya keterlibatan masyarakat sebagai penghasil terbesar limbah rumah tangga yang mencemari badan air (sungai) untuk mengelola limbahnya.

Melalui tulisan ini, disampaikan pemikiran 
mengenai pengelolaan lingkungan hidup dalam hal penerapan pengendalian pencemaran air yang lebih efektif, yakni dengan melibatkan 3 (tiga) pelaku utama dalam menjalankan good governance yang terdiri dari pemerintah, swasta dan masyarakat. Jika dievaluasi dari peraturan yang ada yakni: UU Nomor 32 Tahun 2009 tentang Perlindungan dan Pengelolaan Lingkungan Hidup, PP Nomor 82 Tahun 2001 tentang Pengelolaan Kualitas Air dan Pengendalian Pencemaran Air, dan Permen LH Nomor 5 Tahun 2014 tentang Baku Mutu Air Limbah, maka pelaku masyarakat belum banyak dilibatkan dalam pengendalian pencemaran air. Dalam upaya menyusun strategi membangun partisipasi masyarakat dalam pencegahan pencemaran lingkungan, sudah banyak penelitian yang meneliti hubungan antara pengetahuan, pendidikan, pendapatan, sikap dan ketersediaan sarana dengan perilaku masyarakat dalam upaya pencegahan pencemaran limbah dan sampah rumah tangga. Hal yang membedakan dari penelitian lain yang serupa bahwa penelitian ini memanfaatkan profil masyarakat sebagai modal peningkatan peran serta masyarakat. Tujuan penelitian ini adalah untuk mengetahui profil masyarakat dan lingkungannya di lokasi penelitian serta untuk menyusun strategi pemanfaatan profil masyarakat tersebut sebagai modal meningkatkan peran serta masyarakat dalam upaya pencegahan pencemaran air.

\section{METODOLOGI}

Penelitian kuantitatif dilakukan pada tahun 2015 di Perumahan Permata Depok Sektor Mirah 1 dan Mirah 2, Kelurahan Pondok Jaya, Kecamatan Cipayung, Kota Depok. Pemilihan lokasi penelitian berdasarkan survey lapangan, pengamatan dan kajian literatur terhadap permukiman teratur di sepanjang Sungai Ciliwung di Kota Bogor, Kota Depok dan DKI Jakarta sehingga diperoleh profil daerah penelitian sebagai berikut :

a. Kawasan perumahan berada di tepi atau sepanjang Sungai Ciliwung.

b. Kawasan perumahan memiliki saluran sanitasi terpusat atau komunal.

c. Kawasan perumahan memiliki saluran pembuangan terpusat menuju Sungai Ciliwung.

d. Tidak memiliki Instalasi Pengolahan Air Limbah (IPAL).

Metode pengumpulan data primer dan data sekunder sebagai berikut:

1. Pengumpulan data primer dengan survei responden melalui penyebaran kuesioner yang bersifat terbuka. Data primer yang dikumpulkan tersaji pada Tabel 1 dan Tabel 2 Bab Hasil dan Pembahasan.

2. Pengumpulan data sekunder dilakukan melalui kajian literatur terhadap dokumen. Dokumen yang dimaksud antara lain adalah data demografi, peta teknis Perumahan Permata Depok, peta unduhan (google map), data instansi lain (LIPI, Kementerian PU dan Perumahan Rakyat, Universitas Trisakti, BLHD Kota Depok dan Kelurahan Pondok Jaya) serta data pemantauan kualitas air Sungai Ciliwung oleh Pusarpedal KLH tahun 2010-2014.

Pengolahan dan analisis data yang dilakukan sebagai berikut:

1. Analisis Isi (content analysis), yakni 
mempelajari dan membandingkan fenomena sosial yang terjadi terhadap dokumen tertulis seperti peraturan, buku, situs internet, surat kabar (8). Analisis ini diperuntukkan bagi data sekunder untuk menyusun kriteria lokasi penelitian dan sebagai dasar penyusunan kuesioner.

2. Analisis Statistik Multivariat, yakni metode statistik yang memungkinkan kita melakukan penelitian terhadap lebih dari dua variabel secara bersamaan. Dengan menggunakan teknik analisis ini maka kita dapat menganalisis pengaruh beberapa variabel terhadap variabel-variabel lainnya dalam waktu yang bersamaan (8). Analisis statistik ini menggunakan program IBM SPSS Statistik Versi 19.

\section{HASIL DAN PEMBAHASAN}

Pengelolaan sumber daya alam yang efektif kerap kali membutuhkan perubahan perilaku dari para penggunanya. Hal ini menuntun para ekologis untuk menggunakan alat penelitian yang dibangun oleh para ilmuwan sosial. Para peneliti dengan latar belakang ilmu eksakta perlu mempelajari disain dan metodologi penelitian sosial untuk pemahaman interdisipliner yang seimbang dari sistem sosial-ekologi (9). Salah satu contoh penerapan kombinasi kedua disiplin ilmu adalah pengembangan rencana strategi pengelolaan kebakaran hutan di Tlaxcala, Meksiko. Dengan kombinasi ilmu sosial dan ilmu ekologis, maka diperoleh pemahaman menyeluruh dari risiko aktual yang terjadi di hutan dan identifikasi pilihan yang didukung masyarakat untuk kegiatan konservasi lahan yang dikelola (10).
Kuesioner sebagai alat penelitian dibagi menjadi 2 (dua), yakni kuesioner dengan responden aparatur pemerintah daerah untuk mendapatkan profil lingkungan lokasi riset serta aparat terkait dan kuesioner dengan responden penduduk setempat untuk mendapatkan profil masyarakat. Masingmasing dibahas secara terpisah sebagai berikut:
A. Profil Lingkungan Aparatur terkait di lokasi penelitian

Data hasil penelitian melalui kuesioner terkait profil aparatur di daerah penelitian pada tabel 1.

Aparat daerah masih sangat kurang mendapatkan bantuan baik sarana pengolahan maupun pengelolaan limbah domestik dari pemerintah di wilayah kerja mereka. Jika ada bantuan maka masih sangat kurang mendapatkan pembinaan terkait dengan bantuan yang diberikan oleh pemerintah di lingkungan kerja mereka. Di bidang pendidikan dan pemahaman tentang limbah domestik atau rumah tangga aparat daerah sudah baik (60\%), begitu juga pemahaman terkait Peraturan Perundang - undangan (PUU) atau peraturan daerah terkait limbah domestik atau limbah rumah tangga. Dengan latar belakang tingkat pendidikan yang tinggi ( $40 \% \mathrm{~S} 1$ ) dan pengetahuan yang cukup baik (diatas 60\%) maka diharapkan para aparatur tersebut bersifat terbuka agar masyarakat bisa berperan dalam pencegahan pencemaran lingkungan air.

B. Profil Masyarakat

Profil masyarakat di lokasi penelitian disajikan pada Tabel 2. Dari hasil tersebut, 
variabel-variabel dapat dikelompokkan menjadi 4 (empat) bagian untuk menyusun strategi pencegahan pencemaran air dengan memberdayakan penduduk atau masyarakat setempat, yakni:

1. Demografi, Pendidikan dan Ekonomi Demografi, pendidikan dan ekonomi adalah data kependudukan yang umum ditampilkan dalam penelitian sosial. Keberadaannya bukan tanpa sebab. Variabel ini menjadi penting karena dapat mempengaruhi minat warga, seperti hasil penelitian di daerah pegunungan Italia tentang strategi pengelolaan hutan berbasis masyarakat, didapatkan bahwa jenis kelamin dan umur dapat mempengaruhi minat warga (11). Jenis kelamin dan umur merupakan sub variabel demografi.

Perubahan di saluran alami serta pencemaran air tanah dan air pemukaan menyebabkan sumber air perkotaan mengalami tekanan. Masuknya bahan pencemar ke dalam sistem air perkotaan meningkat karena interaksi antara tanah, permukaan dan sistem pengolahan limbah - terutama untuk kota-kota yang tidak memiliki sistem pengolahan limbah memadai (Strauch et al, 2009; Putra \& Baier, 2009) dalam (12).

Penduduk perkotaan pada umumnya menghadapi persoalan yang sama, yakni penyebaran kota, pemborosan sumber daya, pencemaran yang terkonsentrasi, kondisi tidak sehat dan kualitas hidup buruk di beberapa sektor (UNEP 2007) dalam (13). Lokasi riset yang terpilih selain tidak memiliki sistem pengolahan limbah yang memadai, tetapi memenuhi faktor saluran sanitasi yang terkonsentrasi yakni limbah rumah tangga

Tabel 1 : Hasil pengolahan data faktor internal aparat daerah terkait dalam frekuensi (\%) sebagai Profil Aparat Daerah terkait di Perumahan Permata Depok, Sektor Mirah 1 dan Mirah 2, Kelurahan Pondok Jaya, Kecamatan Cipayung, Kota Depok, Provinsi Jawa Barat

\begin{tabular}{clc}
\hline No. & \multicolumn{1}{c}{ Variabel } & $\begin{array}{c}\text { Frekuensi (\%) } \\
\text { N=188 responde }\end{array}$ \\
\hline 1 & Jenis kelamin laki-laki & 73.3 \\
2 & Pejabat struktural & 53 \\
3 & Sarjana (S1) & 40 \\
4 & Sarjana (S2) & 20 \\
5 & Bantuan sarana pengolahan limbah RT di wilayah kerja & 40 \\
6 & Bantuan lain sarana pengolahan limbah dari Pemerintah di wilayah kerja & 33.3 \\
7 & Kegiatan pembinaan terhadap bantuan pemerintah dari pemerintah atau lembaga & 26.7 \\
8 & lainnya & 53.3 \\
9 & Pengetahuan terkait PUU atau Perwali tentang pengolahan limbah RT. & 93.3 \\
10 & Aparat daerah mendukung PUU terkait pengolahan limbah domestik (RT) & 66.7 \\
11 & Aparat daerah sangat mendukung PUU terkait sampah & 53.3 \\
12 & sampah. & \multicolumn{1}{c}{ Aparat paham terkait bentuk dan karakteristik sampah. } \\
\hline
\end{tabular}

Sumber: Hasil penelitian Purwati, Aryantie, Lahtiani, Medyawati \& Ratnaningsih (2015) 
yang masuk ke selokan yang menuju ke Sungai Ciliwung melalui satu saluran. Untuk itu diperlukan informasi mengenai gaya hidup penduduk dalam mengelola limbahnya, terutama limbah yang masuk selokan tersebut sebagai salah satu variabel dalam penelitian ini.

Hasil penelitian menunjukkan bahwa mayoritas responden penelitian adalah lakilaki dewasa (54.3\%) berumur 41-50 tahun. Data tersebut bersama dengan data pendidikan dan ekonomi untuk mengetahui lebih lanjut profil penduduk dalam rangka menyusun rancangan penelitian dengan penetapan target (kelompok masyarakat yang menjadi sasaran). Terlihat bahwa mayoritas responden berpendidikan tinggi (S1), bekerja (profesi wiraswasta/swasta) tanpa profesi tambahan, pengeluaran sebulan $\geq$ Rp. 1.500.000,- (Satu juta lima ratus ribu Rupiah) dan penghasilan sebulan $\geq$ Rp. 5.000.000,-(Lima juta Rupiah). Informasi tambahan berupa profesi istri menjadi data penting mengingat penelitian ini melibatkan peran masyarakat secara berkelanjutan. Dengan responden (kepala keluarga) yang bekerja, maka kelompok penduduk yang diharapkan dapat aktif berpartisipasi dalam penelitian adalah para istri (ibu rumah tangga).

2. Persepsi Masyarakat terhadap Sampah dan Pengetahuan tentang Sampah. Persepsi masyarakat menjadi relevan sebagai komponen inti dari keberlangsungan kehidupan sosial dan kelestarian lingkungan hidup (9). Persepsi masyarakat terhadap sampah dapat menunjukkan kecenderungannya dalam mengelola sampah di lingkungannya. Hasil penelitian diperoleh bahwa 70,7\% masyarakat paham terhadap pengertian sampah dan setuju dengan regulasi terkait sampah. Di sisi lain $56 \%$ penduduk belum paham benar mengenai karakter sampah serta $55,4 \%$ penduduk belum paham mengenai dampak yang ditimbulkan dari sampah.

3. Gaya Hidup

Ada hubungan tingkat pendidikan masyarakat dengan perilaku pengelolaan sampah, seperti hasil penelitian berikut menunjukan bahwa tingkat pendidikan dan pendapatan berpengaruh secara positif terhadap sikap keluarga dalam pengelolaan sampah rumah tangga (14). Gaya hidup masyarakat di lokasi penelitian merupakan gaya hidup masyarakat yang sudah maju dengan tingkatan ekonomi kelas menengah ke atas, hal ini didukung oleh data kuesioner profil individu yang berpendidikan tinggi dengan penghasilan di atas 5 juta rupiah sebulan dan penduduk membuang sampah dalam seminggu kurang atau sama dengan 7 (tujuh) kali. Mayoritas penduduk paham dan tahu tentang sampah dan jenis sampah juga mengetahui dan paham terhadap jenis jamban dan saluran limbah yang baik. Tetapi mayoritas hanya sekali mendapat penyuluhan tentang sampah dan limbah rumah tangga.

4. Pengelolaan Limbah Rumah Tangga Pengelolaan sumberdaya alam dan pengawasan sumber pencemar acak 
(non-point source/ NPS) merupakan tantangan hingga saat ini (15). Lokasi penelitian yang terletak di Daerah Aliran Sungai (DAS) Sungai Ciliwung adalah salah satu contoh sumber pencemar NPS yang perlu dikelola baik dari sisi lingkungan, ekonomi, maupun sosial. Pengelolaan DAS secara keseluruhan merupakan gabungan dari pengelolaan lahan dan pengelolaan air (15) ditambah dengan pengelolaan sosial ekonomi seperti di lokasi penelitian yang merupakan lokasi permukiman, sehingga kita tidak dapat mengabaikan keberadaan masyarakat yang berada di dalamnya. Sebagai lokasi permukiman, untuk pengelolaan limbah rumah tangga perlu melibatkan penduduk secara langsung. Kemauan penduduk untuk berpartisipasi antara lain dapat dilihat dari kemauan untuk terlibat dan membayar (willingness to pay) peningkatan kualitas air dalam hal ini kualitas air di saluran pembuangan limbah rumah tangga yang menuju ke Sungai Ciliwung.

Data kuesioner menunjukkan bahwa pengelolaan limbah rumah tangga di daerah penelitian sudah didukung oleh saluran sanitasi yang sudah baik dan masyarakat bersedia mengelola limbah rumah tangga yang dihasilkan tetapi kemauan masyarakat dalam membayar iuran untuk pengolahan air limbah masih rendah yaitu sebesar Rp. 5.000,- sampai dengan 10.000 ,- per bulan. Karakteristik ini menjadikan modal bahwa masyarakat sudah paham tentang lingkungan tetapi kemauan berpartisipasi dan untuk terlibat dan terutama untuk membayar (willingness to pay) masih perlu ditingkatkan.

\section{Strategi yang perlu dipersiapkan}

Sesuai dengan profil masyarakat dan lingkungan di lokasi penelitian yang

Tabel 2. Hasil pengolahan data faktor internal masyarakat dalam frekuensi (\%) sebagai Profil Masyarakat Perumahan Permata Depok, Sektor Mirah 1 dan Mirah 2, Kelurahan Pondok Jaya, Kecamatan Cipayung, Kota Depok, Provinsi Jawa Barat.

\begin{tabular}{|c|c|c|c|}
\hline \multicolumn{2}{|c|}{ NO. } & VARIABEL & FREKUENSI (\%) \\
\hline \multicolumn{4}{|c|}{ A. Demografi } \\
\hline 1 & Jenis kelamin responden & : laki-laki & 54,3 (Sedang) \\
\hline 2 & Umur responden & : 41-50 tahun & 59,6 (Sedang) \\
\hline \multicolumn{4}{|c|}{ B. Pendidikan dan Ekonomi } \\
\hline 1 & Pendidikan & $: \mathrm{S} 1$ & 68,6 (Baik) \\
\hline 2 & Profesi & : wiraswasta/swasta & 79,3 (Baik) \\
\hline 3 & Profesi tambahan & : tidak ada & 82,4 (Baik) \\
\hline 4 & Profesi istri & : tidak ada & 63,3 (baik) \\
\hline 5 & Pengeluaran sebulan & $: \geq \operatorname{Rp} 1.500 .000,-$ & 60,1 (Sedang) \\
\hline 6 & Penghasilan sebulan & :> Rp 5.000.000,- & 51,1 (Sedang) \\
\hline
\end{tabular}




\section{Lanjutan}

\begin{tabular}{|c|c|c|}
\hline NO. & VARIABEL & FREKUENSI (\%) \\
\hline \multicolumn{3}{|c|}{ C. Persepsi Masyarakat terhadap Sampah } \\
\hline 1 & Penduduk mengerti dan paham tentang pengertian sampah. & 70,7 Sedang) \\
\hline 2 & Penduduk setuju dengan adanya pengaturan sampah dalam Perda/PP/Kepmen. & 67,6 (Sedang) \\
\hline 3 & $\begin{array}{l}\text { Mayoritas penduduk setuju jika diharuskan untuk memperhatikan masalah persampahan, } \\
\text { terkait dengan aturan persampahan. }\end{array}$ & 72,9 (Sedang) \\
\hline 4 & Penduduk paham tentang bentuk dan karakteristik sampah. & 44,0 (Sedang) \\
\hline 5 & Mayoritas penduduk mengetahui dampak atau kerugian yang ditimbulkan dari sampah. & 44,6 (Sedang) \\
\hline \multicolumn{3}{|c|}{ D. Pengetahuan tentang Sampah } \\
\hline 1 & $\begin{array}{l}\text { Hampir semua penduduk mengetahui akan akibat dari penggunaan air sungai sebagai air } \\
\text { minum. }\end{array}$ & 99,5 (Baik) \\
\hline 2 & Mayoritas penduduk mengetahui tentang frekuensi membersihkan tempat penampungan air. & 77,1 (Sedang) \\
\hline 3 & Hampir semua penduduk mengetahui bentuk jamban yang baik untuk digunakan. & 97,9 (Baik) \\
\hline 4 & Hampir semua penduduk mengetahui dimana tempat membuang hajat yang baik. & 96,8 (Baik) \\
\hline 5 & Pemahaman mengenai jarak yang baik antara sumur dengan WC 6-10 meter. & 41,5 (Sedang) \\
\hline 6 & $\begin{array}{l}\text { Hampir semua penduduk mengetahui saluran pembuangan WC/MCK disalurkan ke septic } \\
\text { tank. }\end{array}$ & 95,7 (Baik) \\
\hline 7 & $\begin{array}{l}\text { Air buangan yang berasal dari dapur rumah dibuang melalui saluran buangan ke selokan } \\
\text { semen. }\end{array}$ & 76,1 Sedang) \\
\hline 8 & Mengetahui saluran pembuangan air limbah ternak yang baik. & 24,0 (Buruk) \\
\hline 9 & Penduduk mengetahui saluran pembuangan air limbah yang baik. & 75,5 (Baik) \\
\hline 10 & Penduduk mengetahui lokasi tempat pembuangan sampah. & 96,8 (Baik) \\
\hline 11 & Penduduk mengetahui tentang sampah organik. & 94,1 (Baiak) \\
\hline
\end{tabular}

\section{E. Gaya Hidup}

1 Penduduk membuang sampah dalam seminggu adalah $\leq 7$ (tujuh) kali.

92,6 (Baik)

2 Penduduk membuang sampah ke angkutan sampah.

85,1 (Baik)

3

Penduduk pernah mendapatkan penyuluhan atau informasi tentang kesehatan lingkungan yang berkaitan dengan sampah.

69,7 (Sedang)

Penduduk hanya mengikuti penyuluhan atau mendapat informasi tentang sampah 1 (satu) kali.

80,9 (Baik)

Jenis sampah yang paling banyak dibuang ke saluran rumah tangga adalah air sisa cucian piring, sayur dan buah.

71,8 (Sedang)

6 Penduduk membersihkan tempat penampungan air bersih seminggu sekali.

68,6 Sedang)

Mengetahui jenis jamban yang paling baik.

99,5 (baik)

Mengetahui saluran pembuangan air limbah yang baik.

78,7 (Baik)

Mengetahui lokasi tempat pembuangan sampah yang baik.

96,8 (baik)

10 Mengetahui tentang sampah organik.

94,7 (Baik)

11 Mengetahui contoh yang termasuk sampah organik.

93,1 (Baik)

\section{F. Pengelolaan Limbah Rumah Tangga}

1 Mayoritas penduduk memiliki saluran pembuangan limbah yang baik dan benar.

2 Mayoritas penduduk bersedia mengelola limbah (sampah) dapur masing-masing.

80,9 (Baik)

3 Mayoritas penduduk mau membantu dalam pelaksanaan pembangunan.

78,7 (Baik)

4 Mayoritas penduduk mau membantu membayar iuran dana pembangunan.

76,6 (Baik)

Mayoritas penduduk mau membantu perawatannya (membersihkan sumbatan, mengganti

78,7 (Biak)

tanaman yang tua, membuat kompos). 
berpendidikan tinggi dan berpenghasilan menengah ke atas dengan gaya hidup yang lebih moderen, maka profil masyarakat seperti ini merupakan masyarakat yang mudah diarahkan, mudah diberikan pendidikan, lebih kreatif, maka pendekatan pengelolaan dalam rangka pencegahan pencemaran air yang efektif adalah melalui pendekatan secara edukatif (4) misal melalui penyuluhan, pengenalan terhadap teknologi sederhana, ramah lingkungan, bernilai ekonomi. Strategi dalam bentuk edukatif melalui penyuluhan sangat cocok karena mayoritas masyarakat di lokasi penelitian $80.9 \%$ mendapat penyuluhan satu (1) kali.

\section{SIMPULAN}

1. Profil daerah penelitian Mirah 1 dan 2 merupakan kawasan perumahan teratur berada di tepi atau sepanjang Sungai Ciliwung, kawasan perumahan memiliki saluran sanitasi terpusat atau komunal, kawasan perumahan memiliki saluran pembuangan terpusat menuju Sungai Ciliwung, tidak memiliki IPAL,

2. Profil aparatur daerah penelitian dengan pendidikan yang tinggi, pengetahuan pengelolaan limbah yang cukup baik, mengetahui serta paham peraturan terkait lingkungan dan mendukung program pengelolaan lingkungan maka para aparatur tersebut bersifat terbuka,

3. Masyarakat daerah penelitian mayoritas usia produktif, berpendidikan tinggi, memiliki status ekonomi tingkat menengah keatas, gaya hidup moderen, mengerti dan paham akan sampah, bersedia mengelola sampah atau limbah cair rumah tangga. Limbah cair yang dihasilkan mayoritas dari kegiatan dapur dan kamar mandi, mayoritas mengikuti penyuluhan baru satu (1) kali,

4. Masyarakat memiliki kemauan berpartisipasi membayar (willingness to pay) yang masih rendah, dan masih kurang bantuan sarana pengolahan dan pengelolaan limbah domestik dari pemerintah atau pihak lain.

Strategi yang diperlukan untuk peningkatan peran serta masyarakat dalam rangka pencegahan pencemaran khususnya air adalah secara edukatif. Strategi edukatif berupa penyuluhan terkait pengelolaan limbah domestik sesuai karakteristik limbah yang dihasilkan oleh masyarakat. Pendekatan startegi teknologi tidak menutup kemungkinan untuk dilakukan berupa teknologi sederhana dan ramah lingkungan sesuai dengan profil masyarakat di lokasi penelitian.

\section{DAFTAR PUSTAKA}

(1) Sabardi L. 2014. Peran Serta Masyarakat dalam Pengelolaan Lingkungan Hidup Menurut UndangUndang Nomor 32 Tahun 2009 Tentang Perlindungan dan Pengelolaan Lingkungan Hidup. Yustisia Edisi 88 Januari-April 2014; hal. 67.

(2) Aminatun T. Upaya Penanggulangan Pencemaran Air. [diakses tanggal 4 Agustus 2016]. Tersedia di

(3) http://staff.uny.ac.id/sites/default/ files/pendidikan/Dr.\%20Tien\%20 Aminatun,\%20S.Si.,M.Si./Peran\%20 Serta $\% 20$ Masyarakat $\% 20$ dalam $\% 20$ Up a y $\% 20$ Penge 1 ola an $\% 20$ Lingkungan\%20Hidup.pdf

(4) Undang-undang Nomor 32 Tahun 2009 tentang Perlindungan dan Pengelolaan Lingkungan Hidup. 
(5) Jumianto. Upaya Penanggulangan Pencemaran Air; 2011 [diakses tanggal 4 Agustus 2016]. Tersedia di http:// jumianto.blogspot.co.id/2011/03/ upaya-penanggulangan-pencemaranair.html

(6) Agustiningsih D, Sasongko SB, Sudarno. Analisis Kualitas Air dan Strategi Pengendalian Pencemaran Air Sungai Blukar Kabupaten Kendal. Semarang. Universitas Diponegoro. Jurnal Presipitasi. Vol. 9 No.2. ISSN 1907-187X. September; 2012

(7) Suprijanto I, Lubis A, Zalbawi S. Keikutsertaan Masyarakat dalam Mengatasi Pencemaran Lingkungan di DKI Jakarta. Bul. Penelit. Kesehat. 17 (3); 1989.

(8) Purwati SU, Aryantie MH, Lahtiani S, Medyawati, Ratnaningsih D. Inventarisasi Karakteristik Limbah Domestik di Sungai Ciliwung: Aplikasi SANITA untuk Pengelolaan Limbah Domestik di Sungai Ciliwung Melalui Pemilihan Daerah Percontohan. Laporan Hasil Penelitian. Serpong: Puslitbang Kualitas dan Laboratorium Lingkungan; 2015.

(9) Babbie E. The Practice of Social Research. California: Thomson Wadsworth; 2007.

(10) Sheridan RAS, Fulé PZ, Lee ME, Nielsen EA. Identifying Socialecological Linkages to Develop a Community Fire Plan in Mexico. Conservation \& Society. Oct-Dec 2015, Vol. 13 Issue 4, p395-406. DOI: 10.4103/0972-4923.179884 [diakses tanggal 15 Agustus 2016]. Tersedia di http://web.b.ebscohost.com/

(11) St. John FAV, Keane AM, Jones JPG, Milner-Gulland EJ. Robust study design is as important on the social as it is on the ecological side of applied ecological research. Journal of Applied Ecology. Dec 2014, Vol. 51 Issue 6, p1479-1485. DOI: 10.1111/1365-2664.12352 [diakses tanggal 15 Agustus 2016]. Tersedia di http://web.b.ebscohost.com/

(12) Paletto A, Meo ID, Cantiani MG, Maino F. Social Perceptions and Forest Management Strategies in an Italian Alpine Community. Mountain Research \& Development. May 2013, Vol. 33 Issue 2, p152-160 [diakses tanggal 12 Agustus 2016]. Tersedia di http://web.a.ebscohost.com/

(13) Strohschön R, Wiethoff K, Baier K, Lu L, Bercht AL, Wehrhahn R, et al. Land Use and Water Quality in Guangzhou, China: A Survey of Ecological and Social Vulnerability in Four Urban Units of the Rapidly Developing Megacity. International Journal of Environmental Research. Spring 2013, Vol. 7 Issue 2, p343-358. 16p [diakses tanggal 18 Agustus 2016]. Tersedia di http://web.a.ebscohost. com/

(14) Pickett S, Buckley G, Kaushal S, Williams Y. Social-ecological Science in the Humane Metropolis. Urban Ecosystems. Sp 2011, Vol. 14 Issue 3, p319-339. 21p. DOI: 10.1007/ s11252-011-0166-7 [diakses tanggal 18 Agustus 2016]. Tersedia di http:// web.a.ebscohost.com/

(15) Putra HP, Taufiq AR, Juliani A. Studi Hubungan antara Tingkat Pendidikan dan Pendapatan Keluarga terhadap 
Sikap dalam Pengelolaan Sampah Rumah Tangga (studi kasus di Desa Condongcatur, Depok, Sleman, Yogyakarta). Jurnal Sains dan Teknologi Lingkungan ISSN: 20851227 Volume 5, Nomor 2, Juni 2013 Hal. 91-101

(16) Grazhdani D. Contingent Valuation of Residents' Attitudes and Willingness to-Pay for Non-point Source Pollution
Control: A Case Study in AL-Prespa, Southeastern Albania. Environmental Management. Jul 2015, Vol. 56 Issue 1, p81-93. DOI: $10.1007 / \mathrm{s} 00267-$ 015-0480-6 [diakses tanggal 22 Agustus 2016]. Tersedia di http:// web.a.ebscohost.com/ 